From the Pediatric Department, State University, 59 Oestersingel, Groningen, The Netherlands

\title{
Nutritional Status as an Important Factor in the Health Status of the Adult
}

by

\author{
J.H.P. JONXIS
}

\begin{abstract}
Matnutrition in the first year of life may cause permanent damage to the individuat. There may be a permanent retardation in growth if the malnutrition is a semious one and the food intake is sleverely insufficient over a longer period specially when malnutrition occurs in the first months after birth, it may cause da mage to the central nervous system.

As long as the breast-fed child gets enough breast milk, it is wnlikely that serious problems arise. The decline in feeding in many developing coumtries is a serious problem, especially becanse thie atternatives for humam milk ane not always avaitable, owing to economic factors. In the countries of the Western world thene exists just the opposite problem; owing to partial over-nutrition abnormalities in fat metabolism may occur, which may influence the health of the individual later on in life.
\end{abstract}

*) Invited Paper at the Third National Indonesian Paediatric Congress, Surabaya 1-6 July, 1974 .

Received 4th. August 1974. 
Since the great infectious diseases, which in the first decennia of this century sitill determined to a great extent the health conditions of a popullation do not play a role anymore in western countries, it is possible to estimate the influence of nutrition of the child on the health condation of the adult more exactly. But it stidl remains difficult to collect precise data, as the nutrition of every popudation and also that of the young child, is changing continuously.

The present adults have in many cases been fed in their infancy, 30-40 years ago, very much differently from the children of today. The reason for the increasing initerest in nutrition is found in the fact that, in spite of the enormous progress in medical treatment, the health condition in western society, is not a very good one. The average life span of a malle tends to become shorter again. The number of people dying of heart and coronary diseases is increasing. Naturally, one wonders about the cause of this; nutrition in infancy may be one of the causes of the artenilosolerosis in the relatively young adult male.

It is known, that nutrition influences growth. If the growing individual is malnourished, his growth rate decreases. An important phenomenon, that was studied for the first time by McCance and Widdowson, may be noticed, namely the fact that the somewhat older experimental animal catches up its growth if it gets enough food after being starved for some time. If the malnourishment takes place during intra-uterine life, or soon afiter birth, however, the growth retardation cannot be corrected when laiter on enough food is available.

This phenomenon is an indication, that malnutrition alt an early age has a much more severe effect than malnutrition during a somewhat later phase of development. In those phases of growth in which the number of cells in the body increases rapidly and cell differentialtion is still in progress (for the human being the period before and shortly after birth), a lack of nultrients will have greater permanent consequences than later on.

In the human being the development of brain tissue is very rapid in the last months before birth. At the age of two years the growth of the human central nervous system is completed for the greater part, while mosit other organs are still developing. In some cases, for instance in muscle tissue, this growth ils, however, mainly based on enlargement of the cell, and not on an increase of the number of cells. When by a lack of one or more nutrients in a certain critical phase of development the normal cell division and differentiacion has been arrested, this may have a permanent effect on the development of the individual. As this development takes place in a strict time schedule, a later abundant quantity 
and quality of nutrients cannot restore the damage by delayed cell division and differentialtion.

We are well informed about the influence of nutrition in utero on the development of the child. It often occurs that identical twins are born of whom as a result of the pecullaritiles of the placental circulation one is much better nourished than the other.

Likely, both children grow up healthy; the child with the lowest birthweight will however never catch up with the more fortunate itwin.

In $1944-1945$ the circumstances in the Netherlands were thus, that the nutritional condition of the population, alt least in the western part of the counitry, was very bad during a rather shor period of about 8 moniths. Now it is initeresting, that the children who were born in the last months before the liberation at the end of the starvation period, had a lower birth weight than children who were born before and after this period in the same population. The difference was about 240 grams, the normal birthweighit about 3700 grams. Also important is that already 4 months after the liberation the birthweight had normalised itself again. The influence of the mother's nutrition on the child's birthweight is most marked in the last months of pregnancy. We can assume that severe malnutrition of the child before birth and in the first year of life may have a per- manent influence on the development of the later individual. This is of spe. cial importance for many nonwesitern countries, in which the sutrition of mother and chill is ofiten not optimal. Especially when breast feeding is supplemented with a nutrittion that is poor in proteins and rich in carbo: hydrates (banana, rice) the risk of protein malnutrition is high, the protein percentage of human milk being low.

While in the western world a lack of aron, fluor and vitamin $D$ are more or less likely to occur, in many itropical areas a lack of protein, vitamin $B$ and in some countries of iodide in the food are frequently found. The main risk in the westiern world for the infant born a terme with a normal birthweight is not malnutrition, but partial over-nourishment. The use of fal, both in quantity and quality, is a main problem in the western world. Overnutrition with carbohydrates (starch and saccharose) is closely linked with the problem of fat overnutrition. At the moment of birth the human being has already a fairly large quantity of fat tissue. After birth the number of fat cells still increases, but the possibility of producing new fait cells decreases gradually and is very limited in the adult, if still present at all.

An infant that builds a considerable fat layer, will have more fat cells than a persion who did not have an excessive fat layer in this youth. The- 
refore, in a person who was thin at first and gained weight later, this increase of weight is achieved with a relativeily restricted number of fat cells, which have more or less a maximal size. On the other hand, the individual who has formed a too great number of fat cells in infancy, has a greater capacity to store fat later on. And if this person has once lost weight, that is, if his fat cellis have given up a great part of the stored fat, he has what I should like to call, a great number of "hungry" fat ceils. He will be more liable to accumulate fat once more and to increase in weight on a somewhat more liberal food-intake than the persion who became fat at a more advanced age.

As we know that an overweight is a disadvantage for an individual who is gettihng older, we may assume that a diet on which a young child accumulates extra subcutaneous fat, will be harmful during adult life. The fat layer of the overweight baby needs not to be formed only by abundant use of fat. For the nutrition that is rich in sugars and flours can promote also fat deposits.

The fat composition of infant nutrition has different aspects. Mother's milk is relatively rich in fat which contains a rather high percentage of unsaturated fatty acids. Infant nutrition based on cow's millk has a divergent falty acid composition it contains more fatty acids with Iong saturated chains, C16, C18. Babies whose nourishment contains cow's milk have markedly higher blood cholesterol levels than children mainly fed on mother's millk during the first half year of life. When we give the child an infant formula in which butter fat is replaced by vegetable oils, rich in unsaturated fatty acids, C 18-2, we find blood cholesterol values which are not higher than that. of the child fed on mother's milk, or even somewhait lower. When we keep these children on a diet with vegetable oils, rich in unsaturated fatty acids, the blood cholesterol percentage is found to be lower than in children who are on a dieit of fatty acids with long saturated chains (buitter fat).

In view of the relation that exilsts during later life between arterio-sclerotic vascular abnormalities and the blood cholesterol level, it uls not unlikely that the nature of the fat that is used in the first year of life is a factor in the development of arterio sclerosis in adult life. We shall only be certain about this when larger groups of children, whose dietary fat in infancy had been vegetable fat, for instance maize oil, have reached adulthood, and we have got an tinsight inito the degree of arterio-sclerotic vascular abnormalities in this group.

Diets, which are rich in unsaturated fatty acids, make high demands on the vitamin $E$ supply of the individual. Fortunately, many vegetable oils (maize oil, sunflower seed oil, soy oil) have high vitamin $\mathrm{E}$ valu- 
es, while they are also wich in the essential fatty acid, linoleic acid. One has to take into account, that there exists an inborn error, which is rather frequenit in many populations, in which at an early age the total li poid and cholesterol percentages of the blood tend to rise markedly. Carriers of thiis hereditary error tend to get arterioscleroitic vascular diseases at relativeily early age. For this group, which already at an early age can be localized in our population by screening, a suitabile diet, poor in saturated faltity acids, eventually saccharose, and relatively rich in unsaturated fatty acids and vitamin $\mathrm{E}$, is important.

Which practical conclusions can be drawn from the previous discussion? Firsitly, that the healthy baby should not be overfed, while vegcitable oils, rich in poly-unsaturated fatty acids, should be preferred to wutter fat.

So far about the influence of the nutrition of the young child on the later state of health in the western population. The situation is different in many areas outside Europe. There, the child is often already born of a malnourished mother, whille it moreover is exposed to total or partial mainutrition in infancy. Mortality is high in these children. The children that stay alive and grow up, will never gain the length they are genetically capable of. In the last ten years much attention was paid ito the ques- tidon : to what exitent severe malnutrition in utero and protein malnuitrition in the first year of life threaten the normal developmenit of the central nervous system. It has been found that in the severelly malnourished child, the development of the central nervous sysitem may be permanently reltarded. This was demonstrated both by microscopic and enzymologic research. Thils damage cannot or hardly be compensated during the next phase of development. It is very difficult to find out to which extenit these disturbances influence later behaviour and learning achilevements. Malnourished children mostlly grow up under the least optimal circumstances and their behaviour and learning achievements depend on environmental factors.

The Rotterdam children who were born at the end of the hunger winter 1944-1945 and hadi a low birthweighit, show no signs of retardation in mental development. Their mothers were however, not chronically malnourished, and in most children the diet was, although in callories insufficient, not too unbalianced.

It is known that a reasonably high percentage of the children who are born in the western world with a considerably low birthweight, due to extra-uterine malnutrition, show mental reitardation later on. Other children from this group, however, developed normally. In our present opinion, the nutrition of these children, 
even in the recent past; was often not optimal: According to our recent views we exposed them to moderately calorie malnutrition in the critical first weeks of life. Our feeding techniques have improved considerably, and we now give 150 cal. per kg. body weight daily instead of $100 \mathrm{cal}$.

We shall have to wait unitil these dysmature infants, who have got these high calloric diets, go to school before we will be able to detect small abnormalitiles in intellectual develo. pment. We shall only in five or six years be able to judge the question: is our view on the nutrition of this group better than in the past? It is very impontant to study the mental development of the dysmature child, that of the in utero malnourished chilld, especially about the connection between nutrition and mental development. It can give us a better insight on the large problems about infant nutrition in tropical countries. We hope that we can help our colleagues there with useful informatilon. However, it is already clear now that adequate breast-feeding is still the best nutrition for the child, and that the food of the child after weaning should contain more protein than human milk contains. 